\title{
Application of stable isotopes on bioaccumulation and trophic transfer of arsenic in aquatic organisms around a closed realgar mine
}

\author{
F. Yang ${ }^{1,2,3}$ \& C.Y. Wei ${ }^{1,2}$ \\ ${ }^{1}$ Institute of Geographic Sciences and Natural Resources Research, Chinese Academy of Sciences, Beijing, P.R. China \\ ${ }^{2}$ Key Laboratory of Land Surface Pattern and Simulation, Chinese Academy of Sciences, Beijing, P.R. China \\ ${ }^{3}$ University of Chinese Academy of Sciences, Beijing, P.R. China
}

\begin{abstract}
Arsenic (As) bioaccmulation and trophic transfer were studied in various species of aquatic organisms from the streams and a reservior (Zaoshi Lake) around Shimen realgar mine, which had been closed since 2001. The As concentrations in top soils, sediments and water were decreasing with the distance from the central mining sites, indicating the As mining activities had still produced eminent impact on As contamination around the mine. Throughout the sampling sites, the As in biota was ranked in an order of tadpole $>$ crab $>$ frog $>$ loach $>$ other fishes. The $\delta^{13} \mathrm{C}$ and $\delta^{15} \mathrm{~N}$ values in the same species of organisms varied greatly with sites, suggesting the impact of diet variation on the trophic levels of the same species in the food chain. The trophic levels for various species of organisms were determined as from 1.25 to 3.76 based on $\delta^{15} \mathrm{~N}$ values. In streams, As levels were much higher in lower trophic organisms, but were quite stable at higher trophic levels, indicating no bio-magnification of As in the food chain, while in the reservoir organisms had much lower arsenic concentrations but obvious biomagnification trend through the food webs. Moreover, the As speciation, including iAs(III), iAs(V), MMA, DMA, AsB and other species were analyzed to explore the biotransformation of As and the sources and bio-transfer of organic As in the food chain. It was found that the organic As species increased with trophic levels in streams, while in reservoir they showed opposite patterns.
\end{abstract}

\section{INTRODCTION}

Arsenic (As) is a pervasive environmental toxicant andu carcinogen that can pose significant health risks to humans and animals (Mandal \& Suzuki, 2002; Smedley \& Kinniburgh, 2002). As toxicity depends on not only its total concentration but also its chemical speciation $(\mathrm{Ng}, 2005)$. As loading from mines has long been a public concern, with serious health consequences for residents living in As-contaminated areas. To explore the As accumulation and transformation throughout the food webs, surface water, sediment, soil, aquatic organisms were collected from Zaoshi Reservior used as a reference site and five study sites along the streams where metal contaminants had been discharged from the abandoned mine. The findings of this research could provide important information for understanding the mechanisms of As bioaccumulation in As-contaminated environments and for assessing the potential environmental impacts of elevated As concentrations on mining activities at the realgar mine area.

\section{METHODS}

\subsection{Total arsenic analysis}

The total As content in samples was determined by ICP-MS (DRC-e, PerkinElmer, Waltham, USA.) following acid digestion. Initially, about $200-300 \mathrm{mg}$ freeze-dried powders were directly weighed into a $25 \mathrm{~mL}$ graduated vessels. After which $5 \mathrm{~mL}$ of concentrated $\mathrm{HNO}_{3}$ was slowly added to the samples, and then left overnight in order to digest gently covered with a perforated glass stopper. In the following morning, the vessel was carried out on a hot plate at $120^{\circ} \mathrm{C}-140^{\circ} \mathrm{C}$ for complete digestion until the solution became transparent and about $1 \mathrm{~mL}$ solution remained. After cooling, about $2 \mathrm{~mL} \mathrm{H}_{2} \mathrm{O}_{2}$ was added and heated for an hour, and then transferred to a $20-\mathrm{mL}$ tube. The tube was brought to volume with ultra-pure water for analysis. To determine the As concentration in soil samples, a portion $(0.3 \pm 0.02 \mathrm{~g})$ was weighed and digested with $10 \mathrm{~mL} \mathrm{HNO}_{3}-\mathrm{HClO}_{4}\left(\mathrm{v} / \mathrm{v}\right.$ 9:1) at $180^{\circ} \mathrm{C}$ on an electric hot plate.

\subsection{Determination of As species}

The dried samples (100-300 mg) was weighed into a $50 \mathrm{~mL}$ polyethyene tube and extracted using a methanol-water mixture $(15 \mathrm{~mL}, 1+1 \mathrm{v} / \mathrm{v})$. The tubes were then placed on a shaker at $150 \mathrm{rpm}$ under room temperature overnight. Then the extracted solution was sonicated in an ultrasonic bath for $30 \mathrm{~min}$ before centrifugation at $3000 \mathrm{rpm}$ for $15 \mathrm{~min}$. The supernatant was transferred into a $25 \mathrm{~mL}$ tubes, while the residue was re-extracted with $5 \mathrm{~mL}$ of $1: 1$ methanol: water mixture following the former procedure. The mixture 


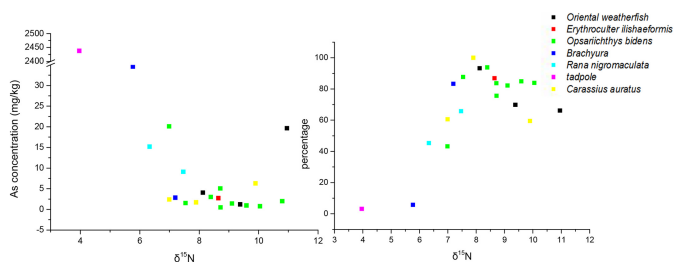

Figure 1. Total arsenic (left) and arsenic speciation (right) of aquatic organisms from the contaminated streams.

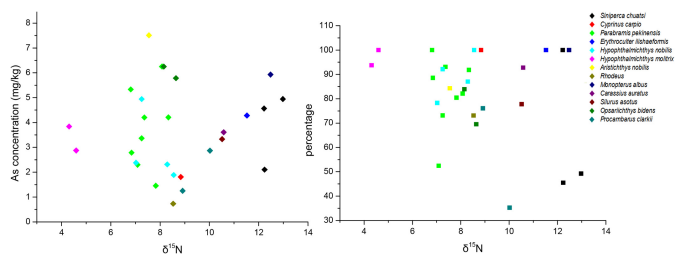

Figure 2. Total arsenic (left) and arsenic speciation (right) of aquatic organisms from the reservoir.

was maintained shaking for $1 \mathrm{~h}$, sonicated for $30 \mathrm{~min}$ and centrifuged for $20 \mathrm{~min}$. The two combined extracts were mixed and evaporated using a pressured $\mathrm{N}_{2}$ gasblowing concentrator until less than $5 \mathrm{~mL}$ solution remained. Before analysis, the samples were filtered with a $0.45 \mu \mathrm{m}$ disposable syringe filters into HPLC vials and stored at $4^{\circ} \mathrm{C}$.

\section{RESULTS AND DISCUSSION}

Analysis of carbon $\left(\delta^{13} \mathrm{C}\right)$ and nitrogen $\left(\delta^{15} \mathrm{~N}\right)$ stables isotopes provides the numerical characterization of trophic level, and as such, we combined it with As to evaluate the biomagnification/biodilution within a freshwater ecosystem. The total As in surface soil, sediments and water were in the range of 35$5000 \mathrm{mg} \mathrm{kg}^{-1}, 43-4543 \mathrm{mg} \mathrm{kg}^{-1}$ and 5-3293 $\mu \mathrm{g} \mathrm{L}^{-1}$, respectively (Figs. 1 and 2). The As concentrations were decreasing with the distance from the central mining sites, indicating that the As mining activities had produced eminent impact on As contamination in Shimen.

The main As compounds identified by HPLC-ICPMS were inorganic As (arsenite, As(III), and arsenate, As(V)), dimethylarsinic acid (DMA) and monomethylarsonic acid (MMA), while arsenobetaine (AsB) and arsenocholine (AsC) were mostly present as minor species. In our study, the proportions of DMA and MMA and the As(III) accounts for higher proportions in the muscle tissue compared to those in the water.
The $\delta^{13} \mathrm{C}$ and $\delta^{15} \mathrm{~N}$ values in the same species of organisms varied greatly with sites, which suggest the impact of diet difference on the trophic levels of the same species in the food chain. The trophic levels for various species of organisms were determined as from 1.25 to 3.76 based on $\delta^{15} \mathrm{~N}$ values. In streams, As levels were much higher in lower trophic organisms, but were quite stable at higher trophic levels, indicating no bio-magnification of As in the food chain, however, the reservoir showed slight arsenic concentrations and obvious biomagnification through the food webs. It is noteworthy that MMA and DMA were the dominant forms of methylated As in the higher trophic level in contaminated streams. The same trends results were reported in the team group previously, which indicating that the lower trophic levels of organisms have a greater ability to accumulate arsenic and higher trophic levels of organisms have a greater ability to methylate arsenic. But the opposite pattern was found in the organisms in reservoir. The reason and mechanisms need further researches.

\section{CONCLUSIONS}

Arsenic contamination from mines is obvious in freshwaters. There are a number of reports documented biodilution of As with increasing trophic levels in freshwater food webs which can be related to many factors. This study gives a full picture of As characterization in both aquatic and terrestrial ecosystem in the As-contaminated area in China. However, a contrast pattern can be found in both total arsenic and its species. No conclusive evidence from the field study has been presented yet, thus further studies are needed.

\section{ACKNOWLEDGEMENTS}

This study was financially supported by the National Natural Science Foundation of China (Grant No. 41571470).

\section{REFERENCES}

Mandal, B.K. \& Suzuki, K.T. 2002. Arsenic round the world: a review. Talanta. 58(1): 201-235.

$\mathrm{Ng}$, J.C. 2005. Environmental contamination of arsenic and its toxicological impact on humans. Environ. Chem. 2(2): 146-160.

Smedley, P.L. \& Kinniburgh, D.G. 2002. A review of the source, behaviour and distribution of arsenic in natural waters. Appl. Geochem. 17(5): 517-568. 